\title{
A critical reflection by participants on microteaching as a learning experience for newly appointed health professions educators
}

\author{
C A Kridiotis, M (Health Professions Education), BTech Diagnostic Radiography; \\ C van Wyk, PhD (Health Professions Education), MSc (Med) Genetic Counselling \\ Division Health Sciences Education, Faculty of Health Sciences, University of the Free State, Bloemfontein, South Africa
}

Corresponding author: C van Wyk (vanwykc2@ufs.ac.za)

\begin{abstract}
Background. A microteaching experience was introduced into an orientation programme for newly appointed health professions educators. Objective. To ascertain whether the participants experienced improved confidence in their lecturing ability after the microteaching experience. Methods. The activity was evaluated by other participants and experts in education by means of a rubric. It was also video-taped to allow for future self-evaluation. Participants' reflections were documented by means of a qualitative questionnaire, with specific criteria designed by the Division Health Sciences Education, University of the Free State, Bloemfontein, South Africa.

Results. Newly appointed educators reflected that the prospect of participating in the microteaching activity initially made them feel apprehensive in terms of 'being evaluated. Once they had completed the activity, they reported that it had been very useful to obtain feedback from peers and expert educators. Collegial relationships in this cohort were strengthened by learning from peers.

Conclusions. Health professions educators found that being evaluated in microteaching was valuable, as they subsequently felt more confident as lecturers and also more competent to implement newly acquired teaching skills.
\end{abstract}

Afr J Health Professions Educ 2019;11(2):41-46. DOI:10.7196/AJHPE.2019.v11i2.1103

Newly appointed health professions educators in the Faculty of Health Sciences (FoHS), University of the Free State (UFS), Bloemfontein, South Africa, are given the opportunity to participate in an orientation programme. The programme is specifically designed for educators in the health professions, in line with international trends ${ }^{[1]}$ and serves to inform educators of their specialised role in training students in the FoHS. Changes in health and higher education legislation in $1997^{[2,3]}$ influenced the role of the medical educator, required new approaches to medical education and proposed that the educator should be both developed and empowered. ${ }^{[4]}$

While it is acknowledged that some newly appointed academic staff members might have teaching experience and/or have had prior educational training, ${ }^{[5]}$ research conducted at the UFS Centre for Teaching and Learning ${ }^{[6]}$ indicated that a critical developmental area identified by educators was 'the ability to engage with students' in lectures. The introduction of a microteaching activity on the final day of the orientation programme was considered to be a suitable developmental tool. Microteaching activities are regarded as providing an environment for teachers to improve their teaching skills and giving them the opportunity to reflect on feedback. ${ }^{[7]}$

\section{Background}

The 2014 course for the newly appointed lecturers' orientation programme at the FoHS was redesigned in consultation with an expert educationalist. The curriculum development cycle as described by Kern et al ${ }^{[8]}$ was used as a guide to identify the topics and flow of the course. The course was presented in 6 blocks: (i) introduction to the FoHS and role as a lecturer; (ii) curriculum design and development; (iii) teaching and learning - study material; (iv) teaching and learning - presentation of study material; $(v)$ assessment and evaluation; and (vi) master lecturer. Key areas in health professions education, such as community-based education and service learning, were also addressed. After each year's orientation programme, improvements that can be made are identified and tailored for the following year's course.

Since 2014, the orientation programme has also included a microteaching activity for participants, with the aim of developing teaching practices and enhancing student-lecturer engagement. Critical reflection by the newly appointed educators was encouraged. The research conducted in this study sought to reflect the views of participants who had been included in the new microteaching activity. This research was based on a German study by Roos et al., ${ }^{[9]}$ who assessed the effectiveness of a 5-day education programme offered to staff members in the medical faculty, using an adopted framework of the Kirkpatrick model. Peer and expert evaluation of participant behaviour during microteaching and participant self-evaluations were recorded. ${ }^{[9]}$

Health professions educators are generally selected and employed based on their qualifications and field of expertise, and not necessarily on their educational experience or abilities. ${ }^{[5]}$ To prepare health professionals for their new role as health sciences educators, academic staff development and continued professional development opportunities are available in faculties of health sciences at tertiary institutions. As highlighted by Singh ${ }^{[7]}$ new models of microteaching are aimed at educators who are already in service, and include peer evaluation with positive reinforcement.

For the final day of the orientation programme, educators were assigned the task of preparing a short lecture, which was presented as a microteaching activity to their peers and a panel of expert educators. The session was video-taped so that participants had the opportunity to self-reflect on their presentation at a later stage. This self-evaluation was combined with peer 
feedback, as well as expert educator feedback. I'Anson et al. ${ }^{[10]}$ reported that they 'identify microteaching as an important stimulus to reflection', and that participation in microteaching activities could enable participants to become aware of previously internalised attitudes and assumptions about learning. They described the value of a microteaching episode as a triangulation: a personal review of a video tape of the lecture, as well as peer and tutor comment, and considered that this is a significant aspect in scaffolding the development of the process of reflection. ${ }^{\text {' }}{ }^{[0]}$ The authors commented that revisiting a microteaching episode through the eyes of a tutor, peers and self, 'is potentially a powerful event', and the process of 'making thoughts about practice explicit, provides a tool that can be used to develop reflective capability. ${ }^{[10]}$

Apart from the lecturing aspect, the emotions experienced by participants engaged in the microteaching experience were also determined. It is not uncommon for participants to experience apprehension ahead of a microteaching activity. Bell ${ }^{[11]}$ reported that while microteaching might be perceived as purposeful, it could also be linked to 'performance'. Participants reported that they experienced discomfort, and that the presence of peers could complicate the interaction. ${ }^{[11]}$ A perceived obstacle that new staff members face, may include gaining acceptance from colleagues, ${ }^{[12]}$ or overcoming isolation and anxiety regarding their new position. ${ }^{[13]}$ This perceived need - to connect with colleagues and develop collegial relationships sooner ${ }^{[12,13]}$ - might be achieved through the orientation programme for newly appointed educators and reinforced through positive peer evaluation of a microteaching activity.

According to Donnelly and Fitzmaurice, ${ }^{[14]}$ advantages of microteaching include opportunities for manageable outcomes, supervision, self-evaluation and feedback, and notably 'immediate guidance in areas of demonstrated shortcomings or in previously identified problem areas by the participant themselves, so that the locus of control in the session always remains with them'. Learning that develops from microteaching experiences has been reported as having an impact on individual teaching practice, influencing how participants approach future course development and delivery. Participants also viewed potential collaboration with colleagues positively. ${ }^{[14]}$

When designing an instrument to be used in the evaluation of a microteaching activity, very clear directives must be considered to inform peer evaluators on the attributes they should seek to evaluate. Not only participant presentation skills, but also actual teaching skills and methods, should form an important part of the assessment of the microteaching presentation of each participant. Subramaniam ${ }^{[15]}$ stressed that the theoryto-practice attributes need to be emphasised by course instructors, and the analytical framework, which sets goals for the microteaching activity, also needs to integrate theories of teaching. In a study by Vander Kloet and Chugh, ${ }^{[16]}$ elements of effective teaching were quantified, and the frequency of occurrence of each element could be calculated during a microteaching activity. These elements included the demonstration of material, preparation and involvement of the learner, as well as a review and summary of the material. A qualitative analysis of themes to be considered in what constitutes 'good teaching' includes speech patterns, eye contact, mannerisms and gestures. ${ }^{[16]}$

Kuswandono $^{[17]}$ reported on the implementation of reflective practice during microteaching activities by asking participants guided questions that included the following: ' $(i)$ What was the most important thing you learned during the class?; (ii) What was something you already knew or had learned but it was reinforced?; (iii) Write down questions or queries you have concerning the topic(s); (iv) What worked well for you in class?; and (v) What did not work well for you in class?'

The role of the expert educationalist in providing comments and group reflection is central to the learning experience. ${ }^{[17]}$ Elements of this reflective approach are also used in current research in the FoHS, UFS.

Kamboj et al. ${ }^{[18]}$ indicated that microteaching activities were beneficial, as immediate and supportive feedback was provided, while presentation and interpersonal skills were improved. Skills included learning to sustain student motivation, explaining clearly, asking questions effectively and learning to manage students effectively. ${ }^{[18]}$ The current research was aligned with the abovementioned international findings, and specific themes that were identified included 'positive aspects' and 'improvement suggestions'.

\section{Methods}

Over a 3-year period, 55 newly appointed and/or inexperienced academics completed the course for newly appointed lecturers in the FoHS, UFS. A total of 35 newly appointed health professions educators participated in a microteaching activity, which was introduced as part of an orientation programme. The number of participants in the microteaching activity were 11 in 2014, 10 in 2015, and 14 in 2016. The activity was purposefully undertaken at the end of the 3-day orientation programme, after the educators had been exposed to topics such as teaching and learning methods, education concepts and terminology, simulation in teaching and guidelines on assessment and feedback. As part of the microteaching experience, each participant prepared a 10 - 15-minute teaching session, which was video-taped and presented to their peers and 4 expert educators. Each participant had to evaluate the microteaching activity of the other participants.

A rubric was used as the evaluation instrument, which had been developed with the personal expertise of health professions educationalists and resources in the FoHS ${ }^{[19]}$ The rubric focused on desirable conduct when presenting a lecture. Participants' reflections were documented through their responses to 3 open-ended questions, with specific criteria designed by the Division Health Sciences Education, FoHS, UFS. The open-ended items were: ' $(i)$ I liked your lecture because ... ; (ii) you can improve your lecture by ...; and (iii) additional information or needs to be addressed.'

The second part of the study was qualitative and made use of a questionnaire that focused on the participants' reflections on their emotions before and after the microteaching activity. They were also asked to reflect on and describe aspects and outcomes of what they had learnt from observing others and from feedback.

\section{Ethical approval}

Informed consent was obtained from participants to use all collected data for research and publication purposes. The data were edited, categorised and summarised by both researchers, and attention was paid to identify common themes in the responses. Ethical approval to conduct the study was obtained from the Ethics Committee, FoHS, UFS (ref. no. ECUFS 213/2013).

\section{Results}

Thirty-five newly appointed academics participated in the microteaching session that was evaluated by, on average, 4 expert educationalists on the last day of the course. 


\begin{tabular}{|c|c|}
\hline Categories & Responses from experts \\
\hline Preparedness & The practical component of the presentation was very well prepared \\
\hline Clear introduction & The brief overview to put the content of this lecture into context was good \\
\hline Topic knowledge & The lecturer's knowledge base on the topic was well used in lectures \\
\hline Session content & Good use of content $\ldots$ practical application - real life \\
\hline Session structure & $\begin{array}{l}\text { The lecture was well structured and prepared } \\
\text { Good construction and systematic presentation of the lecture were observed }\end{array}$ \\
\hline Use of examples & $\begin{array}{l}\text { The practical examples used during the lecture were valuable } \\
\text { The practical examples used contributed to the clinical aspects of health professions teaching } \\
\text { The lecturer conveyed the essential information by using clinical items and medical models (e.g. a stethoscope) } \\
\text { The mind maps used in the session clearly outlined the important concepts }\end{array}$ \\
\hline Presentation skills & $\begin{array}{l}\text { A good presentation style was used, even incorporating some humour } \\
\text { The lecturer maintained good eye contact, and demonstrated clear voice projection }\end{array}$ \\
\hline Teaching practices and skills & $\begin{array}{l}\text { The lecturer was skilful, presented sensitive information professionally and expertly while using contextual and } \\
\text { relevant examples } \\
\text {... very useful to use actual instruments and integrate a practical component into the theoretical session }\end{array}$ \\
\hline Use of activities & $\begin{array}{l}\text { The use of the prepared class activity added value to the session } \\
\text { It was useful to allow the students to practise with equipment during the practical component of the session }\end{array}$ \\
\hline Use of questions & $\begin{array}{l}\text { Questioning skills were used expertly by the lecturer } \\
\text { The questions were asked in a way that showed consideration for cognitive levels; a variety of question types were asked; } \\
\text { enough time was offered for students to respond } \\
\text { Student answers were repeated; therefore, the class could hear the answer } \\
\text { Incorrect answers were dealt with in a professional manner and students were guided towards the correct answer }\end{array}$ \\
\hline Student engagement & The lecturer immediately involved the students by stimulating discussions and asking questions throughout the session \\
\hline Presentation platforms & $\begin{array}{l}\text { There was a good balance between the use of slides and clinical examples } \\
\text { The slides were clear and legible, with appropriate use of font size and colour } \\
\text { The lecturer made use of multiple presentation platforms ... could move effortlessly between the white board, slides and } \\
\text { clinical examples }\end{array}$ \\
\hline Use of technology & $\begin{array}{l}\text { The lecturer used technology seamlessly ... he was well prepared and tested the technology in the venue before the } \\
\text { presentation } \\
\text { Several videos were incorporated into the presentation, making the session more visual by showing the clinical } \\
\text { procedure in practice ... students could relate to it and it was clear that they enjoyed the material }\end{array}$ \\
\hline Presentation emotions & $\begin{array}{l}\text { It was clear that the lecturer was not only knowledgeable, but also passionate about the content presented } \\
\text { The session was presented with enthusiasm, which also contributed to engage the audience }\end{array}$ \\
\hline
\end{tabular}

From the open-ended section of the evaluation rubric two themes were derived: (i) positive aspects; and (ii) improvement suggestions. Table 1 presents the categories identified in the first theme - positive aspects and includes some of the written responses from the expert educators' evaluations, including 'good construction and a systematic approach to the lecture was observed. When a lecturer directed questions to the audience, it was noted that the lecturer gave 'consideration for cognitive levels of students' and allowed enough time for participants to answer.

The same 14 categories were identified in the analysis of the peer evaluations. Among the responses in each of the categories, 7 elicited the most comments. In the order from most to least commented on, the category 'presentation emotion' ranked highest. Peers seemed to be impressed by the confidence, enthusiasm and passion with which their colleagues presented their particular teaching sessions. The next category most commonly commented on was 'session content', with peer evaluators indicating that they found it interesting and informative. Furthermore, peer evaluations revealed observations that their colleagues 'used relevant examples,' 'engaged their audience,' 'demonstrated excellent topic knowledge', 'used several (different) presentation skills well (e.g. voice projection)', and 'came across as being well-prepared' for the session. The self-evaluations showed that the lecturers perceived themselves 'to be topic experts' and 'to enjoy presenting the information. In terms of self-critique regarding their presentation and teaching skills, they were of the opinion that there was room for improvement.

Table 2 presents categories in the second theme - improvement suggestions - as identified from the analysis of the expert educators' evaluations. The educators provided practical feedback on improvement of presentation skills, use of technology, teaching practices and didactic skills. Similar categories were identified from the peer evaluations of the second theme, i.e. improvement suggestions. Of note was that peers made many more comments about the first theme (positive aspects) of their colleagues' teaching sessions than about how the sessions could be improved. The majority of improvement suggestions from peers related to engagement, time management and presentation skills. In the category 'use of examples', 8 different peer evaluators requested that the presenters should consider audience familiarity with terminology used, especially in medical and scientific fields. The participants' observation that lecturers should ensure that complex terms and concepts be adequately explained, and that time 


\begin{tabular}{|c|c|}
\hline Categories & Responses from experts \\
\hline Introduction phase & Start with a clear introduction and present clear outcomes for the lecture \\
\hline Presentation skills & $\begin{array}{l}\text { Be aware of your movements - avoid swaying left to right } \\
\text { Present the educational content in a more academic manner } \\
\text { Consider voice projection in a larger venue } \\
\text { Be careful not to turn and look back at your slides too often } \\
\text { Voice projection could improve and should be practised } \\
\text { Do not read the information presented from the slides } \\
\text { Speak slower - do not rush through the information }\end{array}$ \\
\hline Engagement & Be more interactive - get students involved \\
\hline Use of examples & $\begin{array}{l}\text { Using examples from practice is very important and useful - but make sure these are carefully selected and address } \\
\text { the required learning outcomes ... in addition, make sure the examples are appropriate }\end{array}$ \\
\hline Presentation platforms & $\begin{array}{l}\text { Consider colours used on slides and font size - one should be able to read the text easily from the back of the class } \\
\text { When using a picture of a figure or table, make sure that it displays clearly } \\
\text { When using a white board and explaining concepts by writing on the board, look back at your audience once in a while and } \\
\text { engage them throughout }\end{array}$ \\
\hline Test technology & $\begin{array}{l}\text { Test sound of video before; it might be very loud } \\
\text { Test technology prior to use, such as the sound of a video, an internet link or an application ... always have a back-up plan } \\
\text { should the technology or equipment fail to work }\end{array}$ \\
\hline Keep to time & $\begin{array}{l}\text { When preparing for your teaching session, plan a timeframe and pace your lecture ... crosscheck the number of slides and the } \\
\text { amount of time per slide } \\
\text { Do not rush over important points, be flexible or plan for extra time to address the concepts }\end{array}$ \\
\hline Questioning technique & $\begin{array}{l}\text { Allocate time for students to indicate whether they know the answer, before providing the answer } \\
\text { Use questions to check that students understood complex terms and/or new information provided } \\
\text { Use questions (where applicable) throughout the lecture, not only at the very end when time has expired } \\
\text { Formulate questions ahead of time (when preparing for the lecture) }\end{array}$ \\
\hline Make eye contact & $\begin{array}{l}\text { Refrain from reading the slides while not looking at the audience } \\
\text { Look at the entire audience, not only those in the front row }\end{array}$ \\
\hline Summarise & Conclude the lecture in a more structured manner and refer back to the session outcomes \\
\hline Compose emotions & $\begin{array}{l}\text { Take a breath and relax - you are doing a good job } \\
\text { No matter how stressed you feel, the students should not be aware of it } \\
\text { If you are nervous, take care that this does not to come across to students as being opinionated and judgemental }\end{array}$ \\
\hline Use of fillers & Avoid use of fillers such as 'umm, okay and ah' between words \\
\hline
\end{tabular}

should be made available to discuss terms and concepts, could improve future student engagement in the FoHS in a practical manner.

On completion of the newly appointed lecturers' orientation programme, the daily reflection activities, as completed by participants, were qualitatively analysed by the researchers. The main findings of the reflection activity are presented in Table 3. The results show that participants initially experienced 'a sense of apprehension' at the thought of participating in the microteaching activity in terms of 'being evaluated'. On completion of the activity, participants reported that receiving evaluation and feedback from peers and expert educationalists had been very useful. They also indicated having gained useful skills from evaluating other participants' teaching sessions. The novice educators reported that they had benefited from applying newly learnt knowledge and putting newly learnt skills into practice. Lastly, collegial relationships in this cohort were strengthened through the experience of the 3-day course.

\section{Discussion}

The participants clearly invested time in the preparation of the microteaching activity, and different styles of teaching, presentation and use of technology were observed by peers and expert educationalists who evaluated the activity. The peer and expert educator feedback was an important reflective exercise, which participants indicated was beneficial to them and could lead to changes in their own teaching and presentation styles. An important question that one of the participants considered was whether one would 'perform' any differently when lecturing to a larger group of students. This could be an area for further research, examining the usefulness of providing peer and expert educator observation and feedback to newly appointed educators in real-life lecturing scenarios, with larger audience groups.

The microteaching activity was not a stand-alone activity, but was preceded by a comprehensive orientation programme, which aimed to develop didactic skills and teaching practices, as well as enhancing student-lecturer engagement, which was appreciated by participants. As the orientation programme was presented by a number of expert educators, each with their own unique style, various teaching strategies and skills were embedded in the programme. These strategies could be reflected on by participants ahead of their preparation of the microteaching activity. One participant commented on the benefit of 'putting theory in practice' and that seeing colleagues experience similar challenges was a valuable experience. Expert educators indicated that participants appeared to have benefited from the orientation programme, presentation skills, technologies and innovative 


\section{Research}

Table 3. Participants' reflections after completion of the microteaching activity

\begin{tabular}{lll}
\hline Themes & Categories & Participants' responses \\
\hline Emotions & Pre-activity emotions & A feeling of scepticism about presenting in front of colleagues \\
& & A feeling of being stressed, negative and anxious to present in front of colleagues \\
& & An initial feeling that the microteaching activity 'was a silly idea', but it was actually a rewarding and good experience
\end{tabular}

Post-activity experience The principle behind the presentations made me realise which areas I had to work on to improve my lecturing skills The microteaching session was very constructive and valuable

A productive day, with practical teaching sessions and evaluations. The question must be asked: Would one 'perform' differently in front of a class of 80 students?

I learnt a good deal in a short period of time

It was good to see the different techniques, styles and approaches to giving a lecture

The practical sessions were excellent, with variety and creativity shown by presenters

I enjoyed the interactive participation, lecturers showed passion and empathy, and participants were successfully engaged

Learning Learning from others I learnt from my peers/colleagues; I would like to continue to collaborate

Watching others gave me ideas on how to improve my lecturing style

It was meaningful; I learnt by watching others present their lectures

It was helpful to get tips and ideas from watching how other academics present their lectures and which methods they use to engage their students

I learnt from peers and identified different ways to teach, which I will use to enhance my own approach to lecturing I learnt a lot from other presenters regarding the methods of conducting a lecture

An opportunity to witness other lecturers in action, to learn and pick up pointers on how I could adjust and modify my own lectures to keep students interested

Learning from feedback Getting constructive criticism from colleagues was enlightening

Feedback was very good and I can apply it to improve my lecturing skills

Feedback and criticism made me understand my own shortcomings

In the end, it was very good to get feedback from colleagues and the expert panel for future personal improvement

What stood out the most for me were the comments from the audience; my perception was that people have

preferences of how they do things and would prefer to see similar approaches from other presenters

I welcomed the comments and advice of my peers and the evaluation panel

Aspects learnt

I learnt about various ways of presenting a lecture, different styles and approaches

It helped me to identify the most important information for the students

It was good to see the different styles and approaches to facilitate lectures; it gave me confidence to attempt different ways, while still obtaining the optimal outcomes

I learnt how to be confident

I saw examples of using technology successfully

I learnt to appreciate the different methods of teaching that colleagues used; I will certainly attempt some of their techniques in the future

I learnt a lot about different ways to engage students

Learning outcome It was good to experience putting theory into practice and see that colleagues experience similar challenges. I was also encouraged to hear that it takes time to successfully engage in all the roles of a lecturer

The master-lecturer session was very valuable as a learning experience, a reflection on what we learnt the past 2.5 days and a summary of the important aspects of teaching and learning

I will be able to use these techniques to facilitate teaching and learning in my academic/clinical department

It was worth attending the sessions; they were very practical and innovative

It was helpful to see in action what we have learnt, as well as to take note of other factors, which one might do subconsciously

A great deal of knowledge was gained by exposure to microteaching; everyone had a different way of teaching and implementing the work we have done

The microteaching activity was the best way to end the course. It was good to consolidate everything in a practical way. It will be easy to recall and apply these skills when giving lectures in the future

The opportunity to present and critique other colleagues was very helpful in implementing newly acquired presentation skills

Excellent reflection of the last 3 days, well demonstrated by the presentations

I learnt a lot and grew personally and professionally

I am filled with new inspiration to teach students, and I am now more content than ever with my decision to pursue an academic career

I will be a better lecturer by applying the knowledge I gained - how to channel the knowledge, communicate, collaborate, support and adapt to new methods of teaching and learning

It was interesting to evaluate various lecturing skills; I definitely learnt ways to improve my own lecturing skills I noted a number of different ways to teach, and gained useful information to apply to my new role as teacher and facilitator 
teaching platforms that they had observed during the previous 2 days of the orientation course. The 'improvement suggestions' documented for feedback were similar to findings reported by Kamboj et al. ${ }^{[18]}$ which indicated that the supportive feedback provided after microteaching activities was beneficial. Microteaching activities, when aimed at in-service educators and where peer evaluation with positive reinforcement was used, could lead to 'a perceptible change in the attitude' of participants, as described by Singh. ${ }^{[7]}$ The newly appointed educators in the current study were already in service and interacting with their students, and could also reflect on these experiences with their peer group. When analysing peer evaluations, few comments were made on 'how the sessions could be improved' compared with the feedback from expert evaluators. This was an expected finding, considering that peer evaluators were also newly appointed colleagues, with varied levels of teaching knowledge and experience.

The second part of the study, which used the qualitative questionnaire, focused on participants' reflections on their emotions before and after the microteaching activity (Table 3). They were also asked to describe aspects and outcomes, reflecting on what they had learnt from observing others and from feedback provided. The reflections of participants highlighted a positive learning experience and improved confidence, similar to the findings of Donnelly and Fitzmaurice. ${ }^{[14]}$ Pre-activity emotions were negative in some cases, but reflections on post-activity emotions showed that participants found the microteaching activity to be a constructive exercise. Participants' comments included that they had observed 'different ways to engage students' and that the activity had served to consolidate new skills that had been learnt - in a practical way.

The learning experience of participants in the microteaching activity, where expert educators, peers and participant lecturers observed and reflected, was shown to be meaningful. Overall, participants found that the orientation programme, which included a microteaching activity, helped them to connect with colleagues and develop collegial relationships in a short space of time.

\section{Conclusions}

In the FoHS, UFS, health professions educators who participated in an orientation programme for newly appointed members of staff, found that a microteaching activity added value to their learning experience. Self-, peer and expert educator evaluation provided valuable feedback, and developed their reflective capabilities regarding their perceptions of teaching, learning and student engagement. The health professions educators reported that they subsequently felt more confident in their lecturing abilities, became aware of their shortcomings and felt competent to practise newly acquired skills. A microteaching activity embedded into a staff development activity was found to empower health professionals in their role as educators.

Declaration. This article is linked to research for CvW's $\mathrm{PhD}$, using the same ethics number.

Acknowledgements. Dr Daleen Struwig, medical writer/editor, FoHS, UFS, for technical and editorial preparation of the manuscript.

Author contributions. Both authors were involved in the conceptualisation, analysis and interpretation of the research; CAK took the lead in writing the article.

Funding. None.

Conflicts of interest. None.

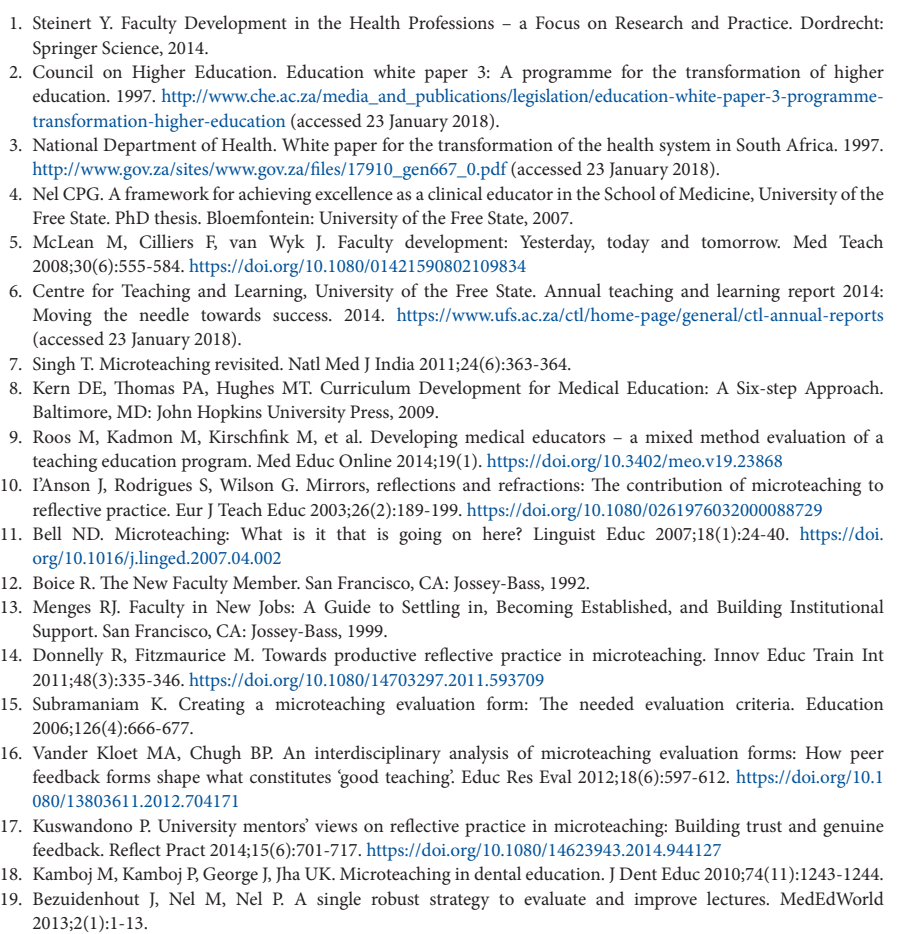
2013;2(1):1-13

Accepted 18 September 2018 